\title{
A REgRa Ótima DE ARMAZENAMENTO DE ARROZ NO BRASIL
}

\author{
Cassiano Bragagnolo $\$$ \\ Vania Di Addario Guimarães ${ }^{\alpha}$ \\ Geraldo Sant'Ana de Camargo Barros ${ }^{\dagger}$
}

\begin{abstract}
RESUMO
Este trabalho pretende aplicar um modelo econômico dinâmico de expectativas racionais para armazenamento de arroz no Brasil com o intuito de modelar a decisão de estocagem. Estas quantidades de estoque maximizam os efeitos de bem-estar oriundos da introdução da estocagem como uma atividade econômica competitiva em um mercado com oferta estocástica, em que todos os indivíduos são maximizadores de lucro com expectativas racionais. Os impactos dependem, principalmente, da informação disponível ao produtor antes do armazenamento ser introduzido, da elasticidade da oferta de área, da especificação da curva de demanda, da taxa de juros considerada e do custo de estocagem. Estas funções e valores foram utilizados para a estimação de um modelo dinâmico de expectativas racionais, através de programação dinâmica estocástica, aproximando uma função de preço esperado e área plantada em função do estoque inicial, fazendo uso de polinômio de quarto grau no estoque, no qual se encontrou uma disponibilidade crítica, a partir da qual ocorrerá armazenamento como uma atividade econômica. Em seguida, procedeu-se à estimação de simulações de longo prazo com o intuito de avaliar os impactos de altos e baixos estoques iniciais no mercado. Os resultados demonstraram que estes impactos podem ser percebidos por cerca de três ou quatro safras.
\end{abstract}

Palavras-chave: mercado de arroz, expectativas racionais, programação dinâmica.

\begin{abstract}
This paper aims to analyze the rice Storage in Brazil through a dynamic economic model of rational expectations in order to model the storage decision. The Storage quantities maximize the welfare in a competitive market with stochastic supply, in which all individuals are profit maximizers with rational expectations. The impacts depend mainly on the information available to the producer before storage is introduced, the elasticity of area supply, the specification of the demand curve, the storage costs and the rate of interest. These functions were used to estimate a dynamic model of rational expectations by a area supply function and expected price according to original storage, using a fourth degree polynomial in the stock. Then, a long-term simulation was estimated with the aim of show the impacts of high and low initial amount of storage in the market. The results showed that these impacts can be perceived for three or four seasons.
\end{abstract}

Keywords: rice market, rational expectations, dinamic programming.

JEL classification: Q11, C61, D41.

§ngenheiro Agrônomo e Doutorando em Economia Aplicada pela ES. E-mail: cassiano@ocepar.org.br, cassiano.bragagnolo@yahoo.com.

a Professora Adjunto do Departamento de Economia Rural e Extensão da Universidade Federal do Paraná, Doutora em Economia Aplicada pela ESALQ/USP.E-mail: addariov@agrarias.ufpr.br .

$\dagger$ Professor Titular do Departamento de Economia, Administração e Sociologia da Escola Superior de Agricultura da universidade de São Paulo, Doutor em Economia pela North Carolina State University at Raleigh. E-mail: gscbarro@ esalq.usp.br.

Endereço para contato: Av. Pádua Dias, 11 CP 9 - Piracicaba - SP - CEP: 13418-900.

Recebido em outubro de 2006. Aceito para publicação em outubro de 2008. 


\section{INTRODUÇÃO}

O comportamento dos preços de produtos agrícolas ao longo do tempo e sua relação com a atividade de armazenamento têm sido objeto de estudo de vários autores. Segundo Barros (2005), o grau de complexidade dessas análises tem variado. Bressler e King (1970) apresentam uma análise bastante simples, considerando apenas dois períodos de tempo. A pressuposição básica necessária é a de que existe perfeito conhecimento sobre as condições de oferta e demanda, tanto presentes quanto futuras. Helmberger e Weaver (1977) substituem essa pressuposição pela de expectativas racionais. Neste caso, pressupõe-se que os agentes de mercado façam suas previsões com base em valores esperados de equilíbrio. Uma série de trabalhos utilizando a abordagem de expectativas racionais no problema de armazenamento tem sido desenvolvida. Podem-se citar como exemplos Wright e Willians (1982), e Lowry, Glauber, Miranda e Helmberger (1987). Modelos desta natureza foram desenvolvidos especificamente para o caso brasileiro por Guimarães (2001), para a cultura do milho. O presente trabalho foi baseado em Wright e Willians (1991) e, principalmente, na proposta desenvolvida por Guimarães (2001).

O objetivo geral foi, por meio de modelos econômicos de programação dinâmica com expectativas racionais, tornar conhecido o modelo para tomada de decisão quanto à formação de estoques de arroz no Brasil, com o intuito de avaliar a decisão de estocagem.

A hipótese básica é de que é possível representar o mercado de arroz no Brasil por intermédio de um modelo dinâmico de expectativas racionais sem intervenção do governo e com uma economia fechada. Esta hipótese foi adotada tendo-se em vista que o arroz não é uma mercadoria com o mesmo grau de internacionalização de commodities como soja e trigo, cujas importações e exportações são extremamente significativas. ${ }^{1}$

Outra hipótese é de que existe neutralidade em relação ao risco, ou seja, os agentes econômicos envolvidos no processo econômico são neutros com relação ao risco inerente à atividade de armazenamento. $\mathrm{O}$ modelo proposto consiste em uma análise anual, uma vez que o interesse se concentra na quantidade de produto estocado na safra t e que é carregado até a safra $t+1$.

\section{MODELO TEÓRICO}

O problema do armazenamento pode ser entendido como a alocação de uma dada quantidade de produto entre consumo corrente e formação de estoques para consumo futuro. Em uma economia perfeitamente competitiva, seria economicamente viável, para um agente individual, armazenar uma unidade a mais de produto, enquanto a diferença entre o preço esperado e o preço corrente fosse maior ou igual ao custo de armazenagem.

1 No caso do arroz, em média nos últimos 20 anos, apenas $8 \%$ da disponibilidade total é proveniente de importação, enquanto 3,5\% desta é exportada. Além disso, a intervenção do governo até foi significativa em alguns períodos, porém não foi decisiva. 
A esperança dos lucros a serem obtidos com a armazenagem da quantidade $S_{t}^{i}$ do período $t$, para o período $t+1$, pela empresa $i$, pode ser representada por:

$$
E_{t} \Pi_{t+1}^{i}=\left(\frac{1}{1+r}\right)\left(E_{t} P_{t+1}\right) S_{t}^{i}-P_{t} S_{t}^{i}-k S_{t}^{i}
$$

em que $r$ é a taxa de juros, $E_{t} P_{t+1}$ denota a média da distribuição das expectativas dos preços que a firma pode encontrar no período $t+1$, formadas no período $t$; $P_{t}$ é o preço em $t$; $k$ é o custo médio unitário de armazenamento, e $S_{t}^{i}$ é o volume a ser armazenado por um agente no período $t$.

Para esta firma tomadora de preços, a condição de primeira ordem de maximização do lucro esperado é:

$$
\frac{\partial E_{t} \Pi_{t+1}^{i}}{\partial S_{t}^{i}}=\left(\frac{1}{1+r}\right)\left(E_{t} P_{t+1}\right)-P_{t}-k=0
$$

Percebe-se que $E_{t} P_{t+1}$ e o preço corrente de mercado $P_{t}$ não são influenciados pela decisão da quantidade estocada pela firma $i$. Isto é, a firma é uma tomadora de preços, o que é condizente com a pressuposição de competição perfeita.

As possíveis relações entre a quantidade de estoque e o lucro esperado, adicionando-se a condição de que o estoque não pode ser negativo, podem ser resumidas através das seguintes inequações:

$$
\begin{array}{ll}
\text { se } & P_{t}+k-\left(\frac{1}{1+r}\right)\left(E_{t} P_{t+1}\right)=0 \Rightarrow S_{t}>0 \\
\text { se } \quad P_{t}+k-\left(\frac{1}{1+r}\right)\left(E_{t} P_{t+1}\right) \geq 0 \Rightarrow S_{t}=0
\end{array}
$$

A análise da estocagem individual em competição perfeita leva à compreensão do papel da arbitragem temporal sobre os preços em dois períodos, mas não fornece elementos suficientes para avançar no problema. Apesar da formulação aparentemente simples apresentada em (3), existem implicações importantes por trás desta condição de arbitragem temporal.

O efeito do armazenamento sobre o mercado é dinâmico, afetando não somente os preços e quantidades consumidas no ano safra corrente e no ano safra seguinte, mas também o preço e a quantidade consumida nos períodos seguintes. Portanto, o efeito do armazenamento é dinâmico e não estático e, como tal, deve ser analisado por meio da teoria do controle. 
A programação dinâmica é uma técnica matemática frequentemente utilizada para se tomar decisões inter-relacionadas, fornecendo um procedimento sistemático para a determinação da combinação de decisões que maximizam a eficácia geral. A programação dinâmica é um tipo geral de abordagem, sendo que as equações particulares de cada problema necessitam ser desenvolvidas para se ajustarem a cada situação analisada em particular.

\subsection{O armazenamento como um problema dinâmico da teoria de controle}

O problema de otimização intertemporal de armazenamento basicamente consiste em estabelecer a quantidade a ser armazenada em determinado ano para consumo nos anos seguintes. Como já foi enfatizado, trata-se de um problema de programação dinâmica, cuja solução admite a existência de um ano no futuro, no qual não ocorrerá armazenamento. Neste ano em particular, o consumo será igual à disponibilidade do produto. Deve-se a Gustafson (1958) a modelagem do armazenamento como um problema da teoria do controle.

No início de um ano agrícola, sabe-se qual o estoque proveniente do ano anterior $\left(S_{t-1}\right)$ e deve-se estimar a quantidade de produto a ser produzida para o ano safra $\left(x_{t}\right)$. A disponibilidade total $\left(I_{t}\right)$ é a quantidade disponível para consumo e estocagem. O problema consiste em determinar qual deve ser a quantidade armazenada para a safra seguinte $\left(S_{t}\right)$, dadas as condições de demanda, oferta, custo de armazenamento e a taxa de desconto intertemporal. A quantidade consumida $\left(Q_{t}\right)$ é determinada simultaneamente. Estas relações são expressas a seguir:

$$
\begin{aligned}
& I_{t}=S_{t-1}+x_{t} \\
& Q_{t}=I_{t}-S_{t} \\
& Q_{t}=S_{t-1}+x_{t}-S_{t}
\end{aligned}
$$

As condições que são relevantes e que devem ser estimadas a priori da derivação da regra de armazenamento são: (1) $\mathrm{O}$ fator de desconto $\alpha$ (igual a $1 /(1+r)$, em que $r$ é a taxa de juros); (2) o custo de armazenamento; (3) as condições de utilização do fator (demanda), e (4) as condições de produção agrícola (oferta). As três primeiras condições podem ser definidas convenientemente pelas seguintes funções:

$K_{t}(S)$ - custo (em reais) de estocar a quantidade $S$ no ano $t$;

$\delta_{t}(Q)$ - valor total (em reais) atribuído a utilização da quantidade $Q$ no ano $t$;

$\chi_{t}(x)$ - distribuição de probabilidade da produção $x$ no ano $t$.

Como uma alternativa ao uso da função de valor total $\delta$, pode-se, caso $\delta$ seja diferenciável, utilizar o valor marginal da função $P_{t}(Q)$, definida como a derivada de $\delta_{t}(Q)$ em relação à quantidade, ou seja:

$$
P_{t}(Q)=\frac{d \delta_{t}(Q)}{d Q}
$$


Segundo Gustafson (1958), para muitos propósitos, o uso do valor marginal da função $P$ se torna mais conveniente do que o uso do valor da função total $\delta$. Verificar-se-á posteriormente que a função de valor marginal pode ser associada à demanda do produto e a função de bem-estar total ao excedente do produtor. Entretanto, inicialmente, formular-se-á a solução em termos da função $\delta$.

Para especificar o critério de otimização, define-se $W_{t}$ (ganho ocorrido no período $t$ ) como o valor total do produto utilizado menos o custo total de estocagem, ou seja:

$$
\begin{aligned}
& W_{t}=\delta_{t}\left(Q_{t}\right)-K_{t}\left(S_{t}\right) \\
& W_{t}=\delta_{t}\left(I_{t}-S_{t}\right)-K_{t}\left(S_{t}\right)
\end{aligned}
$$

Isto ocorrerá quando a quantidade utilizada $\left(Q_{t}\right)$ iguala a disponibilidade total $\left(I_{t}\right)$ menos a quantidade de estoque final $\left(S_{t}\right)$.

A regra de armazenamento pode ser definida como uma função $\left(\theta_{t}\right)$ que explicita a dependência de $S_{t}$ com relação à $S_{t-1}$ e $x_{t}$, ou seja:

$$
S_{t}=\theta_{t}\left(S_{t-1}, x_{t}\right)
$$

A política de estoques para um período de $n$ anos $(t=1, \ldots, n$, em que o ano corrente é $t=$ 1) é definida como o conjunto das regras de armazenamento $\left(\theta_{1}, \ldots, \theta_{n}\right)$.

Se o conjunto de regras de armazenamento for seguido consistentemente, o ganho total em qualquer ano depende da oferta inicial e da regra de armazenamento. Em algum ano no futuro (ano $t$ ), a produção $\left(x_{t}\right)$ é desconhecida, portanto, faz-se necessário o uso da distribuição de probabilidade da produção $\left(\chi_{t}\right)$. Segundo Gustafson (1958), utilizando este valor de distribuição de probabilidade, pode-se, para um determinado conjunto de regras de armazenamento, obter um valor esperado para $W_{t}$, chamado de $E W_{t}$. Desta forma, com as $t$ distribuições de probabilidade da produção $\left(\chi_{2}, \ldots, \chi_{t}\right)$ e se as regras de armazenamento forem conhecidas $\left(\theta_{2}, \ldots, \theta_{n}\right)$, pode-se encontrar $E W_{t}$. Considerando $V_{1, n}$ como a soma dos ganhos esperados nos $n$ anos, trazidos a valor presente para o ano 1 , com uma taxa de desconto constante $(0<\alpha<1)$, obtém-se:

$$
V_{1, n}=W_{1}+\alpha E W_{2}+\alpha^{2} E W_{3}+\ldots+\alpha^{n-1} E W_{n}
$$

Para dados valores da distribuição de produção $\left(\chi_{2}, \ldots, \chi_{n}\right), V_{1, n}$ é uma função de $I_{1}$ e $\theta_{1}, \ldots, \theta_{n}$, desde que $W_{n}\left(I_{n}, S_{n}\right)$ também seja função de $I_{1}$ e $\theta_{1}, \ldots, \theta_{n}$.

Define-se a política ótima de estoque como o conjunto de valores $\theta *_{1}, \ldots, \theta{ }_{n}{ }_{n}$ que maximizam $V_{1, n}$ para qualquer $I_{1}$. Reescrevendo a equação (9) com a finalidade de simplificar a notação, em que o ganho é função do estoque formado e da disponibilidade, obtém-se:

$$
W_{t}=W_{t}\left(I_{t}, S_{t}\right)
$$


Para qualquer valor possível de disponibilidade no ano $n\left(I_{n}\right)$, deve-se encontrar o valor de estoque $\left(S_{n}\right)$, a fim de maximizar $W_{n}\left(I_{n}, S_{n}\right)$. A função que dá um valor para $I_{n}$ como função de $S_{n}$ é a função de estoque ótimo para o ano $n\left(\theta^{*}{ }_{n}\right)$. Com a função $\theta^{*}{ }_{n}$ determinada, o valor ótimo de ganho no ano $n$ é determinado como uma função de $I_{n}$ e, desta forma, pode-se calcular $V_{n, n}^{*}\left(I_{n}\right)$.

Reescrevendo a equação (4) para o ano $n-1$,

$$
I_{n}=S_{n-1}+x_{n}
$$

em que $x_{n}$ (do ponto de vista do ano $n$-1) é uma variável aleatória com distribuição de probabilidade $\chi_{n}\left(x_{n}\right)$. Para obter-se o valor esperado (no ano $n-1$ ) do valor de ganho no ano $n$ (maximizado por $\theta^{*}{ }_{n}$ ), integra-se a função $V_{n, n}^{*}\left(S_{n-1}+x_{n}\right)$ pela função de distribuição de probabilidade $\chi_{n}\left(x_{n}\right)$, tornando a função dependente apenas de $S_{n-1}$. Isto é:

$$
E V_{n, n}^{*}\left(S_{n-1}, x_{n}\right)=\phi_{n-1}\left(S_{n-1}\right)
$$

Esta expressão representa o valor esperado (maximizado) do ganho no ano $n$ como uma função do estoque formado no ano $n-1$. No ano $n-1$, então para qualquer valor possível de $I_{n-1}$, encontra-se o valor de $S_{n-1}$, para maximizar o ganho no ano $n-1$ mais o ganho esperado descontado para o ano $n$, ou seja:

$$
V_{n-1, n}\left(I_{n-1}, S_{n-1}\right)=W_{n-1}\left(I_{n-1}, S_{n-1}\right)+\alpha \phi_{n-1}\left(S_{n-1}\right)
$$

Desta forma, tem-se $S_{n-1}$ como uma função de $I_{n-1}$ (e esta função é $\theta^{*}{ }_{n-1}$ ), a regra de estoque ótimo para o ano $n-1$. Com $\theta^{*}{ }_{n-1}$ determinada, a soma dos valores de ganhos esperados nos anos $(n, n-1)$ é uma função de $I_{n-1}$ e pode ser escrita como $V_{n-1, n}^{*}\left(I_{n-1}\right)$. Maximizando-se (15) com respeito a $S_{n-1}$ :

$$
V_{n-1, n}^{*}\left(I_{n-1}, S_{n-1}\right)=\operatorname{Max}_{0 \leq S_{n-1} \leq I_{n-11}}\left[W_{n-1}\left(I_{n-1}, S_{n-1}\right)+\alpha \phi_{n-1}\left(S_{n-1}\right)\right]
$$

A condição de primeira ordem do problema é representada por:

$$
\frac{\partial V_{n-1, n}\left(I_{n-1}, S_{n-1}\right)}{\partial S_{n-1}}=\frac{\partial W_{n-1}\left(I_{n-1}, S_{n-1}\right)}{\partial S_{n-1}}+\frac{\partial \alpha \phi_{n-1}\left(S_{n-1}\right)}{\partial S_{n-1}}=0
$$

A condição de primeira ordem para maximizar a soma dos ganhos líquidos em dois períodos é de que o ganho de transferência de uma unidade do produto para outro período iguale a perda de não se consumir esta unidade no período atual. $\mathrm{O}$ volume de estoque ótimo é aquele que iguala o ganho marginal futuro à perda marginal hoje, o que corresponde à condição de otimização do armazenamento privado (arbitragem temporal).

A condição de segunda ordem do problema é representada por: ${ }^{2}$

2 Quando se associa a função de demanda à função de bem-estar marginal, a expressão certamente será negativa, uma vez que a demanda é negativamente inclinada como pode ser visto em Guimarães (2001). 


$$
\frac{\partial V_{n-1, n}\left(I_{n-1}, S_{n-1}\right)}{\partial S_{n-1}^{2}}=\frac{\partial W_{n-1}\left(I_{n-1}, S_{n-1}\right)}{\partial S_{n-1}^{2}}+\frac{\partial \alpha \phi_{n-1}\left(S_{n-1}\right)}{\partial S_{n-1}^{2}}<0
$$

Reescrevendo a equação (4) para o ano $n-2$ :

$$
I_{n-1}=S_{n-2}+x_{n-1}
$$

Com o intuito de obter o valor esperado (no ano $n$-2) da soma dos ganhos dos anos $(n-1, n)$ (descontado para o ano $n-1$ e maximizado por $\theta^{*}{ }_{n-1}, \theta^{*}{ }_{n}$ ), pode-se, desta forma, fazendo as definições necessárias obter:

$$
V_{n-2, n}\left(I_{n-2}, S_{n-2}\right)=W_{n-2}\left(I_{n-2}, S_{n-2}\right)+\alpha \phi_{n-2}\left(S_{n-2}\right)
$$

Esta equação é $S_{n-2}$ como uma função de $I_{n-2}$, e esta função é $\theta^{*}{ }_{n-2}$, a regra de estoque ótimo para o ano $n-2$. Com a função $\theta^{*}{ }_{n-2}$ determinada, a soma dos valores de ganhos esperados nos anos $\left(n-2, n-1, n\right.$, descontados para o ano $n$-2) é uma função de $I_{n-2}$ e pode ser escrita como $V_{n-2, n}^{*}\left(I_{n-2}\right)$. Maximizando-se (20) com respeito a $S_{n-2}$ :

$$
V_{n-2, n}^{*}\left(I_{n-2}, S_{n-2}\right)=\operatorname{Max}_{0 \leq S_{n-2} \leq I_{n-21}}\left[W_{n-2}\left(I_{n-2}, S_{n-2}\right)+\alpha \phi_{n-2}\left(S_{n-2}\right)\right]
$$

O procedimento geral para determinar a regra de estoque ótimo no ano $t, \theta^{*}(1 \leq t<n)$, pode ser determinada, uma vez que as políticas ótimas para os anos subsequentes $\left(\theta_{t+1}^{*}, \ldots, \theta_{n}{ }_{n}\right)$ estão agora determinadas. A soma dos valores esperados de ganho nos anos $(t+1, \ldots, n)$ (maximizados por $\theta^{*}{ }_{t+1}, \ldots, \theta^{*}{ }_{n}$ e descontados para o ano $t+1$ ) é uma função conhecida de $I_{t+1}$, chamada $V^{*}{ }_{t+1, n}\left(I_{t+1}\right)$. Reescrevendo a equação (4) para o período $t+1$ :

$$
I_{t+1}=S_{t}+x_{t+1}
$$

em que (do ponto de vista do ano $t$ ) $x_{t+1}$ é uma variável aleatória com distribuição de probabilidade $\chi_{t+1}\left(x_{t+1}\right)$, o valor esperado (no ano $t$ ) de $V_{t+1, n}^{*}$ é obtido através da distribuição de probabilidade, dando origem a uma função de $S_{t}$, chamada $\phi_{t}\left(S_{t}\right)$. Então, para qualquer valor possível de $I_{t}$, existe um valor correspondente para $S_{t}$ que maximiza o ganho no ano $t$ mais a soma esperada, descontada e maximizada dos ganhos nos anos $(t+1, \ldots, n)$. Isto é o mesmo que maximizar:

$$
V_{t, n}\left(I_{t}, S_{t}\right)=W_{t}\left(I_{t}, S_{t}\right)+\alpha \phi_{t}\left(S_{t}\right)
$$

Esta equação é $S_{t}$ como função de $I_{t}$, e esta função é $\theta^{*}{ }_{t}$, a regra de estoque ótimo para o ano $t$. A equação também é a soma dos ganhos esperados nos anos $(t, \ldots, n)$ (descontadas para o ano $t$ ) como uma função de $I_{t}$, chamada $V_{t, n}^{*}\left(I_{t}\right)$. Maximizando-se (13) com respeito à $S_{t}$ :

$$
V_{t, n}^{*}\left(I_{t}, S_{t}\right)=\underset{0 \leq S_{t} \leq I_{t}}{\operatorname{Max}}\left[W_{t}\left(I_{t}, S_{t}\right)+\alpha \phi_{t}\left(S_{t}\right)\right]
$$


Continuando para trás até o ano 1 (ano corrente), tem-se, então, a política ótima para cada ano $\theta^{*}, \ldots, \theta^{*}{ }_{n}$, como o definido pelo princípio de Bellman, e também a soma maximizada dos valores esperados de ganho para todos os anos, como uma função de $I_{1}, V_{1, n}^{*}\left(I_{1}\right)$, obtendose:

$$
V_{1, n}=W_{1}\left(I_{1}, S_{1}\right)+\alpha \phi_{1}\left(S_{1}\right)
$$

Substituindo-se (9) em (25), obtém-se:

$$
V_{1, n}=\delta_{1}\left(I_{1}-S_{1}\right)-K_{1}\left(S_{1}\right)+\alpha \phi_{1}\left(S_{1}\right)
$$

Maximizando (26) com respeito a $S_{1}$ :

$$
V_{1, n}^{*}=\underset{0 \leq S_{1} \leq I_{1}}{\operatorname{Max}}\left[\delta_{1}\left(I_{1}-S_{1}\right)-K_{1}\left(I_{1}\right)+\alpha \phi_{1}\left(S_{1}\right)\right]
$$

Lembrando-se que:

$$
E V^{*}{ }_{2, n}\left(S_{1}, x_{n}\right)=\phi_{1}\left(S_{1}\right)
$$

A expressão (27) é a equação de Bellman para o problema do armazenamento.

O horizonte de planejamento não necessita ser obrigatoriamente finito, uma vez que a variável a ser maximizada é a soma, a valor presente, dos ganhos líquidos atuais e futuros. Mesmo para uma sequência infinita de períodos a soma é finita. Para que isto ocorra, é necessário que a função de valor total seja delimitada acima e abaixo, ou seja, a função de demanda tenha intervalo definido tanto no eixo do preço quanto da quantidade. ${ }^{3}$ Outra condição é de que o fator de desconto $(\alpha=1 /(1+r))$ esteja em um intervalo de valores entre 0 e $1(0 \leq \alpha \leq 1)$, o que ocorrerá para qualquer valor de $r$ entre 0 e $1(0 \leq r \leq 1)$, ou seja, qualquer valor possível de $r$.

Considerando as condições de oferta e demanda e os demais parâmetros do modelo (como custo de armazenagem, taxa de juros, etc...), iguais para todos os anos, pode-se tornar o processo estacionário. Procedendo desta forma, não haverá um conjunto de regras ótimas $\left(\theta^{*}{ }_{1}, \ldots, \theta^{*}{ }_{n}\right)$, mas uma única regra ótima para todos os anos $\left(\theta^{*}=\theta^{*}{ }_{1}=\theta^{*}{ }_{2}=\ldots=\theta^{*}{ }_{n}\right)$.

Gustafson (1958), em seu trabalho pioneiro, demonstrou que o problema do armazenamento também pode ser analisado por meio da função de valor marginal de bem-estar. Retomando a expressão (7):

$$
P_{t}(Q)=\frac{d \delta_{t}(Q)}{d Q}
$$

3 A prova destas condições pode ser encontrada em Gustafson (1958). 
Cada um dos passos utilizados no caso anterior, da função de bem-estar, utilizando-se o valor total $(\delta(Q))$, pode ser refeito para o caso do valor marginal $(P(Q))$. Como no caso anterior, inicia-se o processo a partir de um ano safra $n$ qualquer no futuro.

Para o ano $n$, deve-se pressupor um nível de estoque final $\left(S_{n}\right)$. Se o critério da política é maximizar a soma dos valores esperados dos ganhos através dos $n$ anos, então, $S_{n}=0$. Se o critério é ter um nível específico de estoque ao final do período e maximizar a soma dos valores esperados dos ganhos através dos $n$ anos, então $S_{n}$ deve ser igual a este nível de estoques especificado.

Para o ano $n-1$, deve-se encontrar, para cada valor de $I$, o valor de $S>0$ que satisfaça a seguinte expressão

$$
\begin{aligned}
& \alpha E_{n-1} P_{n}\left(S_{n-1}+x_{n}-S_{n}\right)-k_{n-1}\left(S_{n-1}\right)-P_{n-1}\left(I_{n-1}-S_{n-1}\right)=0, \text { se } I_{n-1}>0 \\
& \alpha E_{n-1} P_{n}\left(S_{n-1}+x_{n}-S_{n}\right)-k_{n-1}\left(S_{n-1}\right)-P_{n-1}\left(I_{n-1}-S_{n-1}\right)<0, \text { se } I_{n-1}=0
\end{aligned}
$$

em que $E$ é o operador de expectativa (esperança matemática) em relação ao nível de produção $\left(x_{n}\right.$, a integral sob a distribuição de probabilidade $\left.\chi_{n}\left(x_{n}\right)\right), \alpha$ é o fator de desconto anual, $P_{n}\left(Q_{n}\right)$ é o valor marginal da função de bem-estar no ano n, $k_{n-1}\left(S_{n-1}\right)$ é o custo marginal de armazenamento no ano $n-1$, ou seja, a derivada do custo total de armazenamento $\left(k_{n-1}\left(S_{n-1}\right)=d K\left(S_{n-1}\right) / d S_{n-1}\right)$. Isto torna $S_{n-1}$ uma função de $I_{n-1}$, e esta função sabe-se que é a regra ótima de armazenamento para o ano $n-1\left(\theta_{n-1}\left(I_{n-1}\right)\right)$. Para os valore de $I_{n-1}$, em que não existirem valores positivos para o estoque $\left(S_{n-1}<0\right)$, tem-se que $\theta_{n-1}^{*}\left(I_{n-1}\right)=0$, ou seja:

$$
\begin{aligned}
& S^{*}{ }_{n-1}=\theta^{*}{ }_{n-1}\left(I_{n-1}\right) \Rightarrow S_{n-1}>0 \\
& \theta^{*}{ }_{n-1}\left(I_{n-1}\right)=0 \Rightarrow S_{n-1}=0
\end{aligned}
$$

Para o ano n-2, tem-se:

$$
\alpha E_{n-2} P_{n-1}\left(S_{n-2}+x_{n-1}-\theta^{*}{ }_{n-1}\left(S_{n-2}+x_{n-1}\right)\right)-k_{n-2}\left(S_{n-2}\right)-P_{n-2}\left(I_{n-2}-S_{n-2}\right)=0
$$

obtendo-se

$$
\begin{aligned}
& S_{n-2}=\theta^{*}{ }_{n-2}\left(I_{n-2}\right) \Rightarrow S_{n-2}>0 \\
& \theta_{n-2}\left(I_{n-2}\right)=0 \Rightarrow S_{n-2}=0
\end{aligned}
$$

De forma geral, tem-se:

$$
\alpha E_{t} P_{t+1}\left(S_{t}+x_{t+1}-\theta^{*}{ }_{t+1}\left(S_{t}+x_{t+1}\right)\right)-k_{t}\left(S_{t}\right)-P_{t}\left(I_{t}-S_{t}\right)=0
$$

obtendo-se 


$$
\begin{aligned}
& S_{t}=\theta^{*}\left(I_{t}\right) \Rightarrow S_{t}>0 \\
& \theta^{*}{ }_{t}\left(I_{t}\right)=0 \Rightarrow S_{t}=0
\end{aligned}
$$

Desta forma, a regra ótima para cada período, $\theta^{*}{ }_{1}, \ldots, \theta^{*}{ }_{n}$ está determinada segundo o princípio de Bellman.

Para a maioria das aplicações práticas, a função inversa da função da regra de armazenamento $(\theta(I))$, definida como $\theta^{-1}(I)$ é única para $S>0$, isto é, a função $\theta(I)$ é monotonicamente crescente para todos os valores de $I$, em que $\theta(I)>0$. O resultado consiste em obter $I$ como uma função de $S$, e esta função é a inversa da regra ótima de armazenamento para o ano em questão $\left(\theta_{t}^{-1}(I)\right)$.

Para o caso de estacionariedade, o procedimento é essencialmente o mesmo, mas as iterações são contínuas até $\theta$ convergir. Isto é, se $\theta^{*}(I)$ é a regra ótima de armazenamento estacionária, então tem-se sucessivas aproximações $\theta_{0}(I), \theta_{1}(I), \ldots, \theta_{m}(I)$, até que $\operatorname{Lim}_{m \rightarrow \infty} \theta_{m}(I)=\theta^{*}(I)$ é obtida, deixando $\theta_{0}=0$ (ou qualquer constante positiva ou qualquer função monotonicamente crescente) e (para $m=1,2, \ldots$. ) encontrando $\theta_{m}(I)$ para satisfazer a condição

$$
\alpha E P\left[\theta_{m}(I)+x-\theta_{m-1}\left(\theta_{m}(I)+x\right)\right]-k\left[\theta_{m}(I)\right]-P\left[I-\theta_{m}(I)\right]=0
$$

Para todos os valores de $I$. Alternativamente, dadas as condições já especificadas de inversão da função de estoque ótimo

$$
\alpha E P\left[S+x-\theta_{m-1}(S+x)\right]-k[S]-P\left[\theta_{m}^{-1}(S)-S\right]=0, \text { para } S>0
$$

A regra ótima de armazenamento estacionária $\theta *(I)$ é a função que satisfaz a equação para todos os valores de $I$, ou seja:

$$
\alpha E P[\theta(I)+x-\theta(\theta(I)+x)]-k[\theta(I)]-P[I-\theta(I)]=0
$$

Alternativamente e dadas as condições especificadas para a inversão da função ótima de armazenamento, tem-se:

$$
\alpha E P[S+x-\theta(S+x)]-k[S]-P\left[\theta^{-1}(S)-S\right]=0 \Rightarrow S>0
$$

Pode-se reescrever a equação anterior como:

$$
\theta^{-1}(S)=S+P^{-1}\left\{\alpha \int_{0}^{\infty} P[S+x-\theta(S+x)] d \chi(x)-k(S)\right\}
$$

4 A prova matemática da equivalência entre os métodos de valor marginal e valor total pode ser encontrada em Gustafson (1958), Apêndice 6. 
em que $P^{-1}$ é a inversa da função de bem-estar marginal $(P)$ e o operador de expectativa (esperança matemática) é substituído pela integral sob a distribuição $\chi(x)$.

Os ganhos e perdas de bem-estar para os consumidores e produtores, devidos à possibilidade de estocagem intertemporal, são os valores dos efeitos esperados para o futuro mais os efeitos no período inicial. Com esta mesma base teórica, é possível fazer a análise para um mercado aberto ou ainda com intervenções governamentais.

Em um mercado competitivo, a solução maximizadora de lucro encontrada para agentes individuais neutros ao risco corresponde à condição de Kuhn-Tucker para um contexto em que as decisões fossem tomadas por um agente controlador central, que visasse a maximização do bem-estar social, ou seja, um armazenamento socialmente ótimo. ${ }^{5}$ O que as difere, basicamente, é quem toma a decisão. Quando se considera um mercado competitivo, a decisão da armazenagem é resultado da ação do conjunto dos agentes do mercado. Quando se considera a teoria do controle, a decisão fica a cargo de um planejador central, no caso, o governo.

Portanto, as abordagens são consideradas equivalentes, levando aos mesmos resultados. A grande diferença é que a única forma de se obter a solução do problema é por meio da modificação da formulação de equilíbrio competitivo com expectativas racionais em uma formulação de otimização dinâmica.

\subsection{Bem-estar}

O valor do ganho a ser maximizado pode ser definido como o valor monetário esperado do produto utilizado menos o custo de estocagem da quantidade armazenada para o período seguinte. Considerando a incerteza inerente à abordagem de eventos futuros, utiliza-se o valor esperado do ganho total. O termo esperado é utilizado no sentido de expectativa racional, o que implica que este depende das distribuições de probabilidade das variáveis aleatórias e que a expectativa é formada de maneira endógena a partir das variáveis do modelo, além das condições de que os agentes usam toda a informação disponível no momento da tomada de decisão e não cometem erros de forma sistemática (GUIMARÃES, 2001). O valor total pode ser definido também como a área sob a curva de demanda analisada a partir da quantidade consumida naquele ano e acima da curva de oferta para o mesmo intervalo, em outras palavras, é o bemestar.

A exemplo de vários outros trabalhos, este considera que não há distorções neste mercado e que não existem outras fontes de instabilidade na economia além do mercado em estudo. $\mathrm{O}$ trabalho também considera que os efeitos de bem-estar podem ser medidos através de mudanças ocorridas no excedente do produtor e do consumidor, que o valor do excedente é satisfatoriamente aproximado por cálculos por meio das curvas de oferta e demanda de mercado e que estas curvas representam o mercado do produto em questão.

5 A prova pode ser encontrada detalhadamente em Samuelson (1971). 
A função de bem-estar marginal pode ser associada à demanda inversa pelo produto e a função de bem-estar com o excedente do consumidor. $\mathrm{O}$ excedente do consumidor é medido por meio da integração da função de demanda inversa em relação à quantidade consumida, ou seja, é definida pela área à esquerda da curva de demanda.

Quando a curva de demanda considerada for Hicksiana (com a utilidade mantida constante e a renda variando), a área à esquerda da curva representa a máxima quantidade que o consumidor pagaria para obter determinada quantidade de produto. Esta medida para as demandas não compensadas tem a propriedade de ser bem definida, ou pelo menos de ser observável. Por outro lado, se as curvas forem Marshalianas (com a utilidade variando e a renda mantida constante), a área à esquerda da demanda não representa uma quantidade observável. O valor monetário do ganho associado aos preços é gerado por uma integral que possui uma trajetória independente. Desta forma, ter-se-ão diferentes ajustes de preço ocasionados pela mesma renda inicial e final, que gerarão diferentes interpretações monetárias do ganho do consumidor em valores de utilidade.

\subsection{Modelo para o mercado de arroz em uma economia competitiva fechada}

Cada produtor decide individualmente quanta área está disposto a destinar ao plantio de determinado produto através da maximização do lucro esperado. Esta relação pode ser apresentada da seguinte forma:

$$
E \Pi_{t}^{i}(1 / 1+r) E_{t}\left(P_{t+1}\right) \times E_{t}\left(y_{t+1}\right) \times A_{t}^{i}-C_{t}\left(A_{t}^{i}\right)
$$

em que $A_{t}^{i}$ é a área agregada a ser plantada pelo produtor $i$ no período $t ; E_{t}\left(P_{t+1}\right) \times E_{t}\left(y_{t+1}\right)$ é a expectativa da receita por unidade de área em $t$, para o período seguinte $t+1 \mathrm{em}$ que $P_{t+1}$ é o preço e $y_{t+1}$ é a produtividade no ano $t+1$; $C_{t}$ é o custo de produção em função da área plantada; $(1 / 1+r)$ é a taxa de desconto, em que $r$ é a taxa de juros. Em um ambiente competitivo, o lucro esperado é zero, desta forma tem-se:

$$
E \Pi_{t}^{i}(1 / 1+r) E_{t}\left(P_{t+1}\right) \times E_{t}\left(y_{t+1}\right) \times A_{t}^{i}-C_{t}\left(A_{t}^{i}\right)=0
$$

e portanto:

$$
(1 / 1+r) E_{t}\left(P_{t+1}\right) \times E_{t}\left(y_{t+1}\right) \times A_{t}^{i}=C_{t}\left(A_{t}^{i}\right)
$$

A condição de primeira ordem para maximização do lucro do produtor em relação à área plantada será:

$$
\frac{E \Pi_{t}^{i}}{\partial A_{t}^{i}}=(1 / 1+r) E_{t}\left(P_{t+1}\right) \times E_{t}\left(y_{t+1}\right)_{t}^{i}-\frac{\partial C_{t}\left(A_{t}^{i}\right)}{\partial A_{t}^{i}}=0
$$


em que $\frac{\partial C_{t}\left(A_{t}^{i}\right)}{\partial A_{t}^{i}}$ é o custo marginal por hectare e $(1 / 1+r) E_{t}\left(P_{t+1}\right) \times E\left(y_{t+1}\right)$ é a receita marginal por hectare em valor presente. $\mathrm{O}$ custo marginal por hectare é igual à receita marginal por hectare. A área agregada a ser plantada atende à condição de equilíbrio dada por (43) e é uma função da receita esperada:

$$
\begin{aligned}
& A_{t}=A\left[E_{t}\left(P_{t+1}\right)\right] \\
& \frac{\partial A_{t}}{\partial E_{t}\left(P_{t+1}\right)}>0
\end{aligned}
$$

tal que

$$
\frac{\partial A_{t}^{i}}{\partial E_{t}\left(P_{t+1}\right)}=\frac{E_{t}\left(y_{t+1}\right) /(1+r)}{\partial^{2} C_{t}\left(A_{t}^{i}\right) /\left(\partial A_{t}^{i}\right)^{2}}>0
$$

pois, por hipótese

$$
\frac{\partial^{2} C_{t}\left(A_{t}^{i}\right)}{\left(\partial A_{t}^{i}\right)^{2}}>0
$$

Como

$$
A_{t}=\sum_{i} A_{t}^{i} \equiv A\left[E_{t}\left(P_{t+1}\right)\right]
$$

segue que

$$
\frac{\partial A_{t}}{\partial E_{t}\left(P_{t+1}\right)}=\sum_{i} \frac{\partial A_{t}^{i}}{\partial E_{t}\left(P_{t+1}\right)}>0
$$

A área cresce em função do preço esperado porque o custo marginal por hectare é crescente. A produção esperada no ano $t\left(x_{t}\right)$ é produto da área plantada no período anterior $\left(A_{t-1}\right)$ e da produtividade esperada em $t\left(y_{t}\right)$.

$$
x_{t}=A_{t-1} \times y_{t}
$$

A quantidade consumida no período $t\left(Q_{t}\right)$ pode ser representada pela seguinte relação

$$
Q_{t}=I_{t}-S_{t}
$$

em que $S_{t}$ é a quantidade estocada do período $t$ para o período $t+1$ e $I_{t}$ é a quantidade disponível para consumo no período $t$. 
A disponibilidade do produto para consumo no período $t$ pode ser descrita pela relação

$$
I_{t}=x_{t}+S_{t-1}
$$

Este volume de produto disponível poderá ser utilizado para consumo ou ser armazenado. Rearranjando a equação (50), tem-se a relação a seguir:

$$
I_{t}=S_{t}+Q_{t}
$$

Uma forma de encontrar a solução para o problema é pressupor que existirá arbitragem intertemporal de preços no mercado através da atividade de armazenamento até que:

$$
\left(\frac{1}{1+r}\right)\left[E_{t}\left(P_{t+1}\right)\right]=P_{t}+k
$$

em que $k$ é o custo marginal de estocagem.

Pressupondo que os consumidores possuem funções de demanda idênticas, a demanda inversa de consumo pode ser descrita por:

$$
\text { se } P_{t}=P\left(Q_{t}\right) \text {, então } P>0
$$

em que $v_{t}$ é o choque aleatório associado à demanda inversa.

Pressupondo-se que as funções de demanda por arroz e oferta de área para plantio de arroz são as mesmas ao longo do tempo, a regra intertemporal de arbitragem pode ser representada por

$$
\begin{aligned}
& \text { se }\left(\frac{1}{1+r}\right)\left[E_{t}\left(P_{t+1}\right)\right] \geq P_{t}+k \Rightarrow S_{t} \geq 0 \\
& \text { se } \quad\left(\frac{1}{1+r}\right)\left[E_{t}\left(P_{t+1}\right)\right]<P_{t}+k \Rightarrow S_{t}=0
\end{aligned}
$$

É importante observar que o preço esperado (baseado em expectativa racional) para o período $t+1$ é uma função do estoque formado no período $t$ e do estoque a ser formado no período seguinte $t+1$

$$
E_{t} P_{t+1}=f\left(S_{t}+x_{t+1}-S_{t+1}\right)
$$

O que se procura é encontrar o valor do estoque no período $t$ que soluciona a expressão apresentada a seguir: 


$$
\left(\frac{1}{1+r}\right) f\left[S_{t}+\left(A_{t} \times y_{t+1}\right)-S_{t+1}\right]-P_{t}\left[S_{t-1}+\left(A_{t-1} \times y_{t}\right)-S_{t}\right]-k=0
$$

No período $t$, a produtividade, o custo de armazenamento, a área e os valores de estoque inicial são conhecidos. A produtividade em $t+1$ e o estoque a ser formado em $t$ e $t+1$ não são conhecidos. A área a ser plantada no período $t$ depende das decisões de estocagem no momento presente $(t)$ e das decisões de estocagem futuras.

\section{MATERIAL E MÉtodos}

Os métodos utilizados para solução exigem que as funções de demanda, oferta de área, o custo unitário de armazenamento, taxas anuais de juros e a distribuição de probabilidades das variáveis aleatórias (produtividade e choques de demanda) sejam conhecidas.

Mantendo-se constantes estes parâmetros para todos os anos, o problema se torna estacionário e, portanto, é possível encontrar a regra de armazenamento ótimo para o equilíbrio, ou seja, em algum momento ocorrerá convergência. Outra condição necessária para que ocorra a otimização é que a função objetivo seja separável.

Segundo Guimarães (2001), a condição suficiente é que a função objetivo seja estritamente côncava em $S_{t}$ e $I_{t}$ e que ambos sejam conjuntos convexos fechados não nulos, ou seja, a função inversa de demanda para consumo deve ser contínua para todo e qualquer $I_{t}$, bem como estritamente decrescente, a função da oferta de área deve ser crescente e contínua e a função do preço esperado deve ser decrescente em relação ao estoque e área plantada.

\subsection{Dados para estimação do modelo}

Além dos dados básicos, são consideradas como informações para o modelo as condições que são relevantes para a sua estimação, devendo estas serem estimadas a priori. Estas condições são: (1) a taxa de juros, (2) o custo de armazenamento, (3) as condições de demanda do produto (função de demanda e choques de demanda) e (4) as condições de produção agrícola (no caso oferta de área e choques de produtividade).

\subsubsection{Função de oferta de área}

A função oferta de área foi estimada por mínimos quadrados ordinários, tendo como variável dependente o custo de produção $\left(C P_{t}\right)$ por unidade de área (hectare), por meio do programa estatístico R. O período analisado foi o compreendido pelas safras entre 1985/86 a 2000/01. As safras de 2001/02 até 2004/05 não foram consideradas devido à falta de dados para o preço dos insumos. 
Os dados de área plantada foram obtidos na Conab. O custo de produção de arroz médio nacional por hectare foi calculado com base em estudos elaborados pela Embrapa (MELOFILHO; RICHETTI, 2000, 2001, 2002; DOSSA, 2002) e pela FNP (AGRIANUAL, 2005). Foram considerados sete tipos de tecnologia de arroz de terras altas e quatro para arroz irrigado, baseados em estudos de 2001 feitos pela Embrapa, ponderando-se pela área plantada com cada tipo de tecnologia ao longo dos anos em análise. Os valores dos preços dos insumos foram obtidos no Departamento de Economia Rural da Secretaria da Agricultura e do Abastecimento do Estado do Paraná (Seab/Deral), admitindo-se que estes sejam representativos da produção nacional. Admite-se neste procedimento que o custo marginal é igual ao custo variável médio de produção, ou seja, não há economia de escala. Embora os custos de produção de arroz sejam bastante heterogêneos ao longo do nosso território, este procedimento foi considerado como representativo para a evolução dos custos de produção de arroz no Brasil, tendo em vista a falta de estudos mais detalhados sobre o assunto. Todos os valores foram deflacionados para dezembro de 2004 através do IGP-DI. O ajuste da equação não foi considerado totalmente satisfatório. Não foram encontradas muitas referências a este tipo de estimativa na literatura. Não havendo metodologia alternativa para a equação de oferta de área, os resultados obtidos foram utilizados. Os resultados das variáveis e os seus testes $t$ são apresentados a seguir:

$$
A_{t}\left(C P_{t}\right)=\underset{(0,509232)}{523,59537}+\underset{(3,575292)}{1,59761} C P_{t}+\varepsilon_{t}
$$

\subsubsection{Função de demanda inversa}

A função de demanda inversa para consumo foi estimada por mínimos quadrados ordinários, por meio do programa estatístico $\mathrm{R}$, tendo como variáveis dependentes o consumo $\left(Q_{t}\right)$ e a renda $\left(R_{t}\right)$. O período analisado foi de 20 anos, compreendendo as safras entre 1984/85 e 2003/04.

A renda utilizada para o cálculo foi a renda média anual divulgada pelo IPEA e baseada na Pesquisa Anual por Amostra de Domicílios (PNAD) do IBGE, completando-se para os anos não disponíveis com a média entre o ano anterior e posterior. O consumo anual foi baseado na série de consumo aparente divulgada pela Conab. A série de preço de arroz utilizada foi baseada na série de preços mensais pagos ao produtor da Fundação Getúlio Vargas/Agroanalysis, tomandose a média anual simples destes preços de janeiro a dezembro e deflacionado-os através do IGPDI para dezembro de 2004.

Os resultados das variáveis e os testes t são apresentados a seguir:

$$
\begin{aligned}
P_{t}\left(Q_{t}, R_{t}, \cup_{t}\right)= & 2,893976-0,000247 Q_{t}+0,000136 R_{t}+z_{t} \\
& (5,05757) \quad(-4,96168)
\end{aligned}
$$

\subsubsection{Choques de oferta}

A análise de distribuição de frequências da produtividade do arroz no País foi feita para o período das safras entre 1980/01 até 2004/05, considerando uma produtividade média de 3,1726 toneladas/ha em um desvio padrão de 0,2777 toneladas/ha. Descontando-se das séries a tendên- 
cia de ganho de produtividade anual e testando-se o tipo de distribuição (normal, triangular ou uniforme), encontrou-se que os dados melhor se ajustam à distribuição normal.

A partir da média e do desvio padrão, aproximou-se uma distribuição de probabilidade para 12 valores, o que equivale à utilização da Quadratura de Gauss (MIRANDA; FACKLER, 2001).

\subsubsection{Choques de demanda}

Para calcular os choques de demanda, computaram-se os resíduos obtidos a partir da regressão da demanda para consumo, com distribuição normal, média zero e desvio padrão de 467,6978 mil toneladas. Note que os valores dos choques de demanda foram computados a partir dos resíduos da estimação da função de demanda ordinária e não da demanda inversa.

Com os valores citados em mãos, construiu-se uma distribuição de probabilidade para sete valores, o que equivale à utilização da Quadratura de Gauss (MIRANDA; FACKLER, 2001).

\subsubsection{Demais parâmetros do modelo}

O custo de armazenamento foi calculado com base nas tabelas de preços divulgadas pela Conab, com um valor de $\mathrm{R} \$ 6,69 /$ tonelada para o ano de 2004. A taxa de juros utilizada foi de $12 \%$ ao ano.

\subsection{Estimação do modelo}

\subsubsection{Função do preço esperado}

A função do preço esperado somente pode ser encontrada através de aproximações sucessivas, o que torna necessário o desenvolvimento de algoritmos. Existem inúmeros métodos para aproximação de funções não lineares. Neste estudo, adota-se o procedimento proposto por Wright e Willians (1991) e por Guimarães (2001), que consiste em uma aproximação sucessiva do preço esperado em função de um polinômio de quarta ordem no estoque. Segundo Wright e Willians (1991), na última iteração, o polinômio deve estar aproximado até a sexta casa decimal.

\subsubsection{Algoritmos encontrados entre o estoque de equilíbrio, produção planejada e disponibilidade corrente}

O objetivo deste algoritmo numérico é encontrar, para qualquer disponibilidade $\left(I_{t}\right)$, níveis de Estoque $\left(S_{t}\right)$ e área plantada $\left(A_{t}\right)$ que resultam das ações de maximização de lucro do processo de estocagem e dos produtores que possuem expectativas racionais sobre o preço no período $\mathrm{t}+1$. 
A relação de equilíbrio entre estoques e disponibilidade está implícita na condição de arbitragem:

$$
P_{t}\left(I_{t}-S_{t}\right)+k-(1 /(1+r)) E_{t}\left(P_{t+1}\left(S_{t}\right)\right) \quad \Rightarrow S_{t}>0
$$

Antes de determinar a função do preço esperado, é importante lembrar que é necessário:

1. Determinar os parâmetros das funções de oferta de área e inversa da demanda para consumo.

2. Determinar o valor do custo $(k)$ unitário de armazenamento.

3. Determinar o valor para a taxa de juros $(r)$ considerada.

4. Construir uma distribuição baseada em pontos de uma distribuição de probabilidade contínua (no caso uma normal) de $j(j=1, \ldots, m)$ valores para a produtividade $y^{j}$, com média $\mu$ e variância, associados às suas respectivas probabilidades $\left(\varpi_{j}\right)$ de acordo com a Quadratura de Gauss (MIRANDA; FACKLER, 2001).

5. Construir uma distribuição baseada em pontos de uma distribuição de probabilidade contínua (no caso uma normal) de $k$ valores para os choques de demanda $z^{k}$, com média zero e variância $\varphi^{2}$ e associados às suas respectivas probabilidades $\left(v_{k}\right)$ de acordo com a Quadratura de Gauss (MIRANDA; FACKLER, 2001).

Não é possível derivar a regra de armazenamento sem antes derivar numericamente a função $E_{t}\left(P_{t+1}\left(S_{t}\right)\right)$, relacionando o estoque corrente com o preço esperado no próximo ano e resolver a condição de arbitragem com o objetivo de obter o estoque associado a cada disponibilidade. De posse de 1, 2, 3, 4 e 5, os passos necessários para encontrar $E_{t}\left(P_{t+1}\left(S_{t}\right)\right)$ podem ser descritos como segue.

Passo 1. Escolher um polinômio $\psi^{0}$ como a primeira aproximação do preço esperado em função do estoque.

Passo 2. Escolher n valores para o estoque $\left(S_{t}^{i}\right)$, igualmente espaçados.

Passo 3. Escolher n valores para a área plantada $\left(A_{t}^{i}\right)$, associados a cada valor de estoque $\left(S_{t}^{i}\right)$.

Passo 4. Multiplicar $A_{t}^{i}$ por cada valor $y_{t+1}^{j}$, gerando uma matriz de produção $x_{t+1}^{j}$. Somar $x_{t+1}^{j}$ a cada $S_{t}^{i}$, obtendo valores de disponibilidade $S_{t+1}^{i j}$. Para cada $S_{t+1}^{i j}$, somar o choque de demanda $z^{k}$, desta forma gerando a matriz de disponibilidade total $I_{t+1}^{i j k}$.

Passo 5. Para cada $I_{t+1}^{i j k}$, resolver numericamente a função implícita

$$
\begin{array}{ll}
P_{t+1}^{i j k}\left(I_{t+1}^{i j k}-S_{t+1}^{i j k}\right)+k-(1 /(1+r)) \psi\left(S_{t+1}^{i j k}\right)=0 & \Rightarrow S_{t+1}^{i j k}>0 \\
P_{t+1}^{i j k}\left(I_{t+1}^{i j k}-S_{t+1}^{i j k}\right)+k-(1 /(1+r)) \psi\left(S_{t+1}^{i j k}\right)<0 & \Rightarrow S_{t+1}^{i j k}=0
\end{array}
$$


A solução consiste em encontrar as raízes de interesse para os valores $S_{t+1}^{i j k}$ e $I_{t}^{i j k}$ que resolvem as equações acima. Esta raiz é obtida através de aproximações sucessivas. Este método é conhecido como método de Newton e pode ser definido para o problema como se segue:

$$
\left(S_{t+1}^{i j k}\right)_{n+1}=\left(S_{t+1}^{i j k}\right)_{n}-\frac{P_{t+1}^{i j k}\left(I_{t+1}^{i j k}-S_{t+1}^{i j k}\right)+k-(1 /(1+r)) \psi\left(S_{t+1}^{i j k}\right)}{\frac{\partial P_{t+1}^{I J K}\left[I_{t+1}^{i j k}-\left(S_{t+1}^{i j k}\right)_{n}\right]}{\partial\left(S_{t+1}^{i j k}\right)_{n}}+\frac{\partial k}{\partial\left(S_{t+1}^{i j k}\right)_{n}}-\frac{\partial(1 /(1+r)) \psi\left[\left(S_{t+1}^{i j k}\right)_{n}\right]}{\partial\left(S_{t+1}^{i j k}\right)_{n}}}
$$

em que $\left(S_{t+1}^{i j k}\right)_{n+1}$ é a aproximação final do valor de estoque final e $\left(S_{t+1}^{i j k}\right)_{n}$ é a aproximação inicial do valor de estoque final.

Faz-se $n$ substituições para o estoque final $\left(S_{t+1}^{i j k}\right)$ e, quando $\left(S_{t+1}^{i j k}\right)_{n+1}-\left(S_{t+1}^{i j k}\right)_{n} \leq \varepsilon$, em que $\varepsilon^{6}$ é um número suficientemente pequeno, temos uma aproximação satisfatória da raiz da equação.

Passo 6. O estoque de equilíbrio obtido determina, simultaneamente, todas as variáveis endógenas, inclusive o preço para cada situação. Com base nestes preços, é possível calcular agora o preço esperado para cada respectiva área inicial.

$$
E_{t}\left(P_{t+1}^{i}\left(S_{t}^{i}\right)\right)=\sum_{j=1}^{m} \sum_{k=1}^{K} P_{t+1}^{i j k}\left(I_{t+1}^{i j k}-S_{t+1}^{i j k}\right)\left(\varpi_{j}\right)\left(v_{k}\right)
$$

Passo 7. Calcular a receita por hectare pelos produtores:

$$
E\left(R^{i}\right)=\sum_{j=1}^{m} y_{t+1}^{j} E\left(P_{t+1}^{i}\left(S_{t}^{i}\right)\right)
$$

Verificar se a área inicial é consistente com a receita esperada por meio da função de oferta de área. Se $A_{t}\left(E R^{i}\right)-A_{t}^{i}>\varepsilon$, em que $\varepsilon$ é um número pequeno, deve-se refazer os passos 1 a 7 . Quando $A_{t}\left(E R^{i}\right)-A_{t}^{i} \leq \varepsilon$, então $A_{t}^{i}$ é a área de equilíbrio.

Passo 8. Uma vez obtidas as áreas de equilíbrio, ajusta-se um novo polinômio do quarto grau $\psi^{1}$ de $P_{t+1}$ em função de $S_{t}^{i}$. Substitui-se $\psi^{0}$ por $\psi^{1}$ e recalculam-se os passos 1 a 8 . O processo deve ser repetido n vezes até que $\psi^{n}-\psi^{n-1} \leq \varepsilon$, em que $\varepsilon$ é um número suficientemente pequeno.

Passo 9. Uma vez obtido o polinômio de $P_{t+1}$ em função de $S_{t}^{i}$, ajusta-se um polinômio do quarto grau $(\varphi)$ do vetor $A_{t}^{i}$ em função do vetor $S_{t}^{i}$. Não sendo satisfatório o ajustamento do polinômio da área em função do estoque, diminui-se o espaçamento dos valores de estoque inicial até que $\varphi^{i}-\varphi^{i-1} \leq \varepsilon$. Feito isto, então $\varphi^{i}$ é o polinômio final.

6 Neste trabalho adotou-se um valor para $\varepsilon=0,00001$. 


\subsubsection{Médias de longo prazo}

O último passo consiste em simular o comportamento das variáveis endógenas ao longo do tempo. Estas médias de longo prazo podem ser obtidas por meio de simulações de Monte Carlo (WRIGHT; WILLIANS, 1991). Os valores das variáveis estocásticas (produtividade e choques de demanda) foram simulados através da função rnorm do programa estatístico R, utilizando-se 2.500 valores com distribuição normal e com as médias e os desvios padrão citados anteriormente. Estes valores foram utilizados para obter as médias de longo prazo das variáveis endógenas. Estas médias de longo prazo foram obtidas através de simulações para um período de dez anos, começando no ano zero, na qual o estoque é zero para o primeiro caso e 3.000 para o outro. Segundo Wright e Willians (1991) e Guimarães (2001), as simulações devem partir de um ano com disponibilidade abaixo ou acima da média, para que possa se verificar como o sistema absorve estes impactos.

\section{Resultados E Discussão}

A Tabela 1 apresenta os valores dos parâmetros utilizados para a estimação do modelo. A geração dos números aleatórios, a distribuição de frequência das variáveis e os cálculos e testes para obtenção da função de demanda e oferta de área foram feitos a partir do programa estatístico R. Todos os demais cálculos e procedimentos numéricos foram realizados através de planilha eletrônica.

\section{Tabela 1 - Dados e parâmetros do modelo}

\begin{tabular}{ll}
\hline Parâmetros & Valores \\
Termo constante & 523,595370 \\
Coeficiente da receita esperada & 1,597615 \\
Demanda Inversa & \\
Termo constante & 2,893976 \\
Coeficiente da renda anual & 0,000136 \\
Coeficiente do preço & $-0,000247$ \\
Renda Mensal considerada (R\$/mês) & 360,000000 \\
Choques de oferta & \\
Produtividade média (toneladas/ha) & 3,172575 \\
Desvio Padrão da Produtividade (toneladas/ha) & 0,277718 \\
Choques de demanda & \\
Média dos choques de demanda & 0,000000 \\
Desvio padrão dos choques de demanda (mil toneladas) & 467,697799 \\
Taxa anual de juros (\%) & $12 \%$ \\
Custo unitário anual de armazenamento (R\$/kg) & 0,006690 \\
\hline
\end{tabular}


Tendo estimado a demanda de arroz para consumo, a oferta de área, os choques de demanda, a produtividade aleatória, o custo de armazenamento físico e a taxa de juros, foi possível estimar o modelo representativo do mercado de arroz no Brasil sem intervenção do governo e para uma economia fechada. O algoritmo utilizado foi basicamente o mesmo descrito por Guimarães (2001).

O algoritmo começa com a escolha de um vetor de estoques iniciais $\left(S_{t}\right)$. Foram escolhidos 19 valores entre zero e 4,5 milhões de toneladas, crescendo a um montante de 250 mil toneladas.

\subsection{A política ótima de estoques e as funções de preço esperado e área plantada}

O modelo gerou uma política ótima de estoques para cada valor de disponibilidade. A disponibilidade total, para as 2.500 simulações, variou de uma quantidade mínima de 8.955,33 mil toneladas até uma quantidade máxima de 11.833,47 mil toneladas. Estes valores foram gerados a partir da combinação dos valores simulados para a produtividade e choques de demanda e dos valores calculados para estoque final do período anterior que definem a área plantada do período seguinte e o preço esperado.

Começa a ocorrer formação de estoques a partir de uma disponibilidade crítica de 11.833,47 mil toneladas. Para valores menores que este, não ocorrerá estocagem, uma vez que os preços de mercado mais o custo não viabilizam a atividade de armazenamento, ou seja, não haverá lucro na atividade.

O estoque a ser formado para a menor disponibilidade simulada (8.955,33 mil toneladas), claramente, é zero, uma vez que este é menor que o valor crítico (11.833,47 mil toneladas). Para a maior disponibilidade simulada (15.950,96mil toneladas), o estoque a ser formado será de 3.696,95 mil toneladas. A plotagem dos valores das 2.500 simulações pode ser observada no Gráfico 1.

A partir dos valores simulados, pode-se definir uma "regra” de estoque ótimo para qualquer disponibilidade de arroz, estoque este sujeito aos pressupostos e parâmetros do modelo. Estes valores podem ser observados no Gráfico 2.

A plotagem dos valores e os parâmetros dos polinômios de quarto grau utilizados como aproximação para o preço esperado e da área em função do estoque são apresentados nos Gráficos 3 e 4 .

No Gráfico 5, são apresentadas as aproximações sucessivas do polinômio de quarto grau do preço esperado em função de estoque. A aproximação utilizada foi a décima segunda. A diferença entre as aproximações a partir do quarto polinômio tornam-se menores, o que demonstra a convergência do modelo. De fato, a diferença entre a sexta e a décima segunda aproximação é bastante pequena. 
Gráfico 1 - Disponibilidade inicial e estoque final de arroz para 2.500 valores simulados

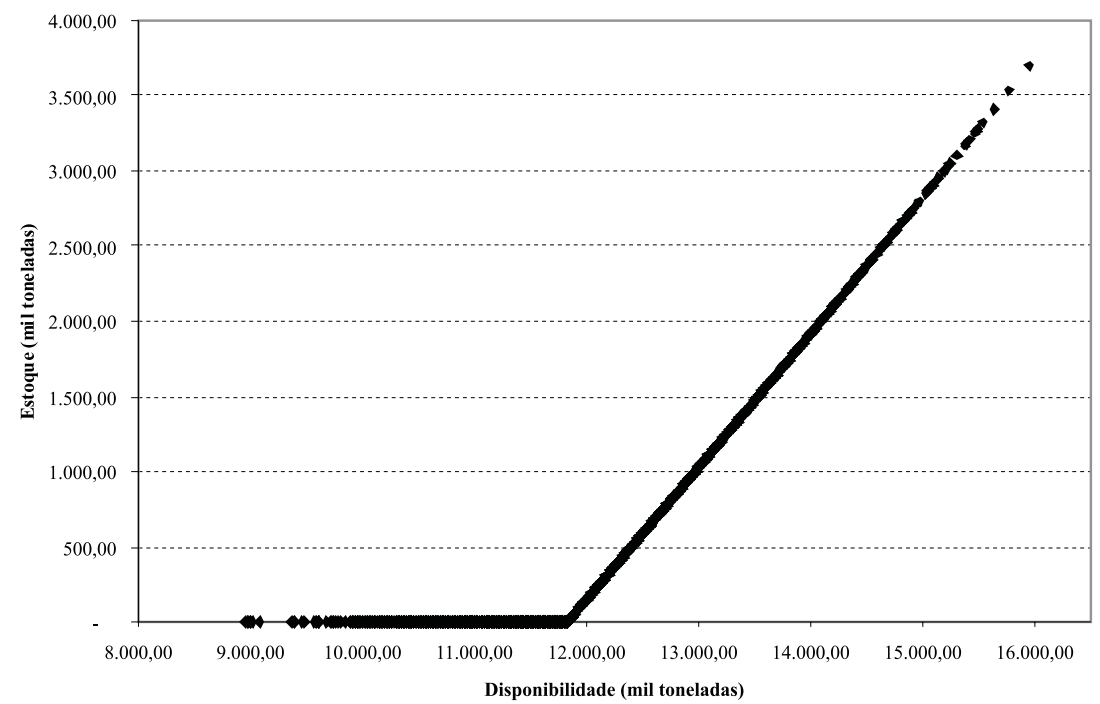

Gráfico 2 - Disponibilidade inicial e estoque final de arroz, "regra ótima"

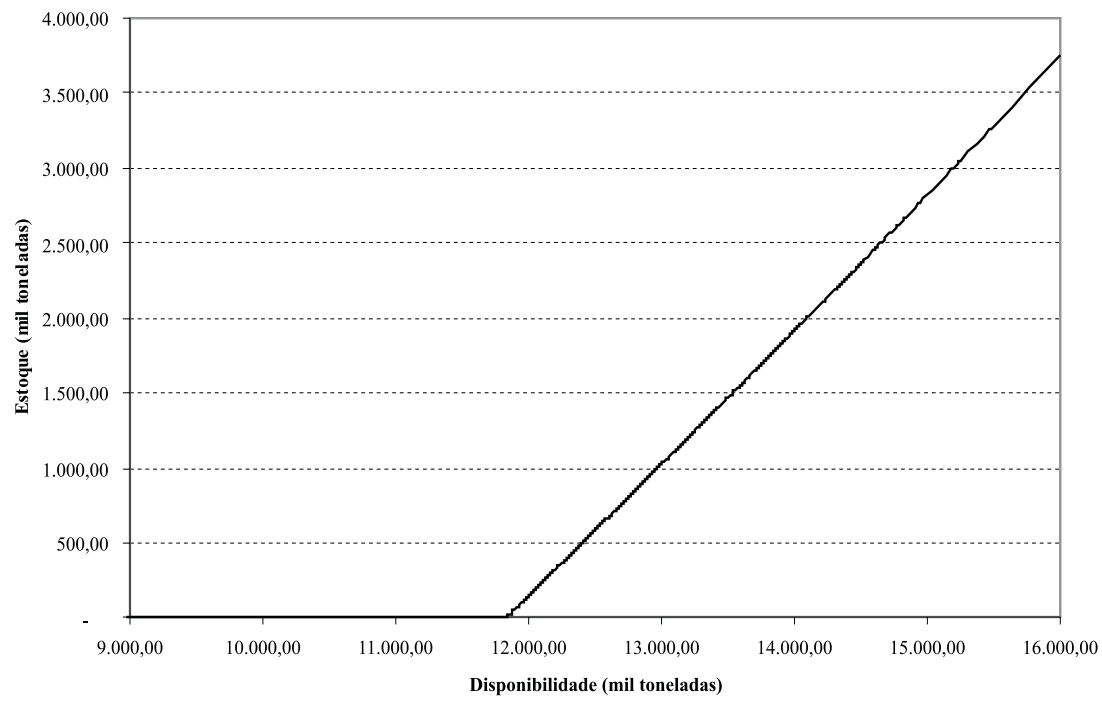




\section{Gráfico 3 - Preço esperado em função do estoque}

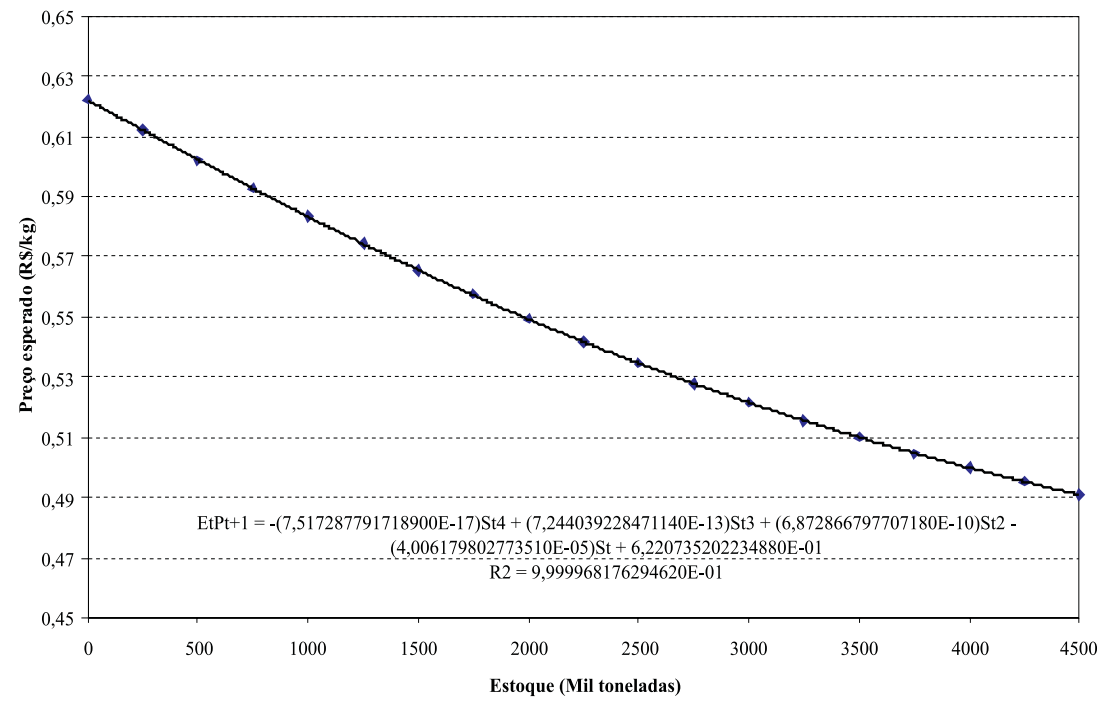

\section{Gráfico 4-Área plantada em função do estoque}

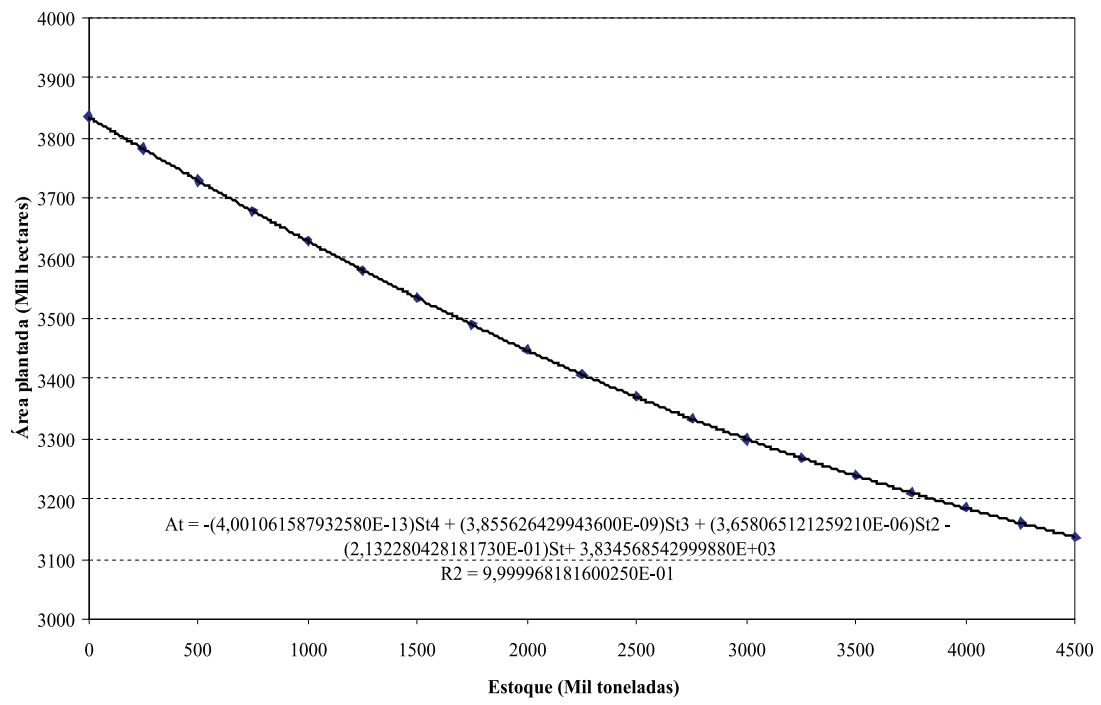




\section{Gráfico 5 - Aproximações do polinômio de quarto grau do preço esperado em função do estoque}

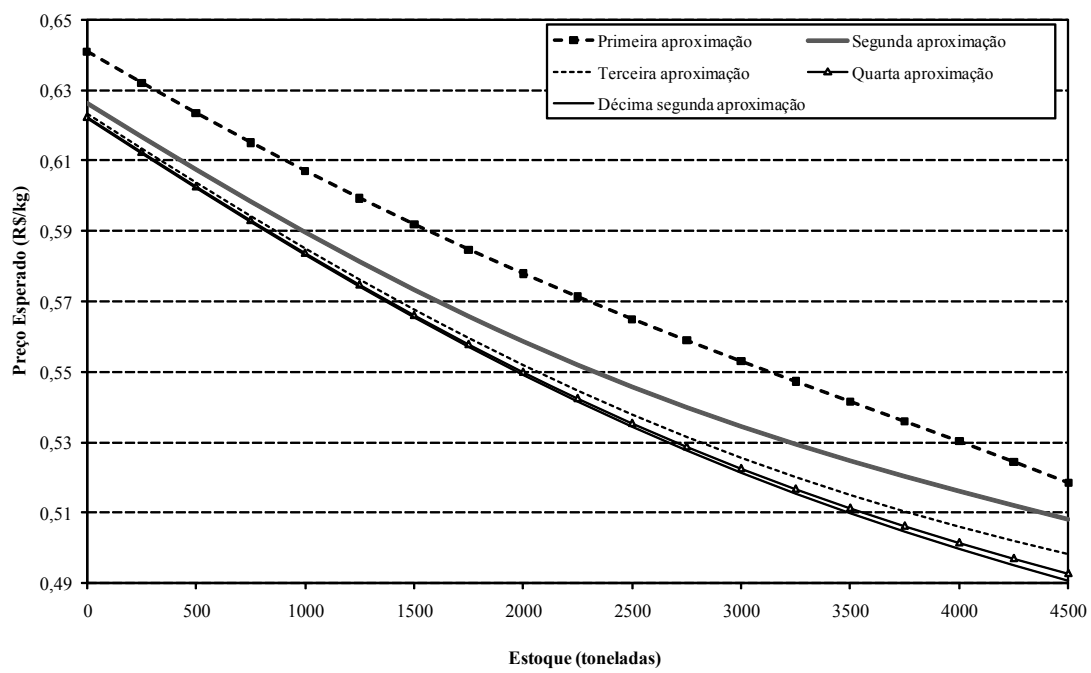

\subsection{Médias de longo prazo}

As médias de longo prazo foram obtidas através de simulações para um período de dez anos com estoques iniciais de 0 e 4.000 mil toneladas. Cada sequência foi simulada 2.500 vezes, portanto, a média apresentada é a média destes 2.500 valores. Este tipo de análise permite verificar de que maneira acontece a absorção ao longo dos anos de um estoque inicial baixo e um alto.

As Tabelas 2 e 3 apresentam as médias de longo prazo para os dois estoques iniciais, nas quais se verifica que as variáveis apresentam o comportamento esperado. Considerou-se como $100 \%$ o maior preço encontrado, que foi o primeiro ano do estoque zero. Altos preços estão ligados a baixos consumos e a área plantada aumenta à medida que se tem estoques mais baixos.

Os valores das variáveis endógenas para os diferentes estoques convergem para valores próximos, já a partir do quinto ano. O valor para o ano final nas duas estimações é extremamente próximo e pode-se verificar que é aproximadamente igual.

O baixo estoque considerado na Tabela 2 é compensado por um aumento da área plantada. No segundo período, o estoque continua um pouco abaixo da média dos períodos subsequentes. No terceiro período, o estoque final já atinge um valor bastante próximo ao dos períodos posteriores. 
Tabela 2 - Médias de longo prazo das variáveis endógenas com estoque inicial zero

\begin{tabular}{lccccccc}
\hline Ano & $\begin{array}{c}\text { Estoque Inicial } \\
\text { (mil ton.) }\end{array}$ & $\begin{array}{c}\text { Produção } \\
\text { (mil ton.) }\end{array}$ & $\begin{array}{c}\text { Disponibilidade } \\
\text { (mil ton.) }\end{array}$ & $\begin{array}{c}\text { Consumo } \\
\text { (mil ton.) }\end{array}$ & $\begin{array}{c}\text { Estoque Final } \\
\text { (mil ton.) }\end{array}$ & $\begin{array}{c}\text { Preço } \\
\text { (\%) }\end{array}$ & $\begin{array}{c}\text { Área } \\
\text { (hectares) }\end{array}$ \\
\hline 1 & 0,00 & $12.142,3$ & $12.159,77$ & $11.590,9$ & 568,88 & $100,00 \%$ & $3.834,57$ \\
2 & 568,88 & $11.794,6$ & $12.365,97$ & $11.683,1$ & 682,87 & $96,34 \%$ & $3.720,66$ \\
3 & 682,87 & $11.756,5$ & $12.427,95$ & $11.700,3$ & 727,62 & $95,66 \%$ & $3.698,54$ \\
4 & 727,62 & $11.717,9$ & $12.447,14$ & $11.715,0$ & 732,17 & $95,08 \%$ & $3.689,53$ \\
5 & 732,17 & $11.714,5$ & $12.439,23$ & $11.706,6$ & 732,64 & $95,41 \%$ & $3.688,87$ \\
6 & 732,64 & $11.712,0$ & $12.437,18$ & $11.713,8$ & 723,42 & $95,13 \%$ & $3.688,96$ \\
7 & 723,42 & $11.721,6$ & $12.424,97$ & $11.704,1$ & 720,83 & $95,51 \%$ & $3.691,01$ \\
8 & 720,83 & $11.722,9$ & $12.456,44$ & $11.706,2$ & 750,29 & $95,43 \%$ & $3.691,36$ \\
9 & 750,29 & $11.685,2$ & $12.426,34$ & $11.711,1$ & 715,26 & $95,23 \%$ & $3.685,64$ \\
10 & 715,26 & $11.734,1$ & $12.446,45$ & $11.719,1$ & 727,35 & $94,92 \%$ & $3.691,83$ \\
\hline
\end{tabular}

1 Inclui os choques de demanda.

Tabela 3 - Médias de longo prazo das variáveis endógenas com estoque inicial de 4.000 mil toneladas

\begin{tabular}{lrrrrrrr}
\hline Ano & $\begin{array}{r}\text { Estoque Inicial } \\
\text { (mil ton.) }\end{array}$ & $\begin{array}{c}\text { Produção } \\
\text { (mil ton.) }\end{array}$ & $\begin{array}{c}\text { Disponibilidade } \\
\text { (mil ton.) }\end{array}$ & $\begin{array}{c}\text { Consumo } \\
\text { (mil ton.) }\end{array}$ & $\begin{array}{c}\text { Estoque Final } \\
\text { (mil ton.) }\end{array}$ & $\begin{array}{c}\text { Preço } \\
\text { (\%) }\end{array}$ & Área \\
\hline 1 & 4000 & 10083,9 & 14101,3622 & 12086,1 & 2015,2763 & $80,36 \%$ & 3184,52 \\
2 & 2015,2763 & 10961,3 & 12979,1287 & 11880,8 & 1098,3643 & $88,51 \%$ & 3457,89 \\
3 & 1098,3643 & 11506,8 & 12593,7561 & 11758,6 & 835,1249 & $93,35 \%$ & 3619,97 \\
4 & 835,1249 & 11652,6 & 12489,3545 & 11729,9 & 759,4317 & $94,49 \%$ & 3669,01 \\
5 & 759,4317 & 11698 & 12450,0154 & 11710,6 & 739,3833 & $95,25 \%$ & 3683,66 \\
6 & 739,3833 & 11707,9 & 12439,7952 & 11714,7 & 725,0482 & $95,09 \%$ & 3687,66 \\
7 & 725,0482 & 11720,6 & 12425,6188 & 11704,4 & 721,2251 & $95,50 \%$ & 3690,7 \\
8 & 721,2251 & 11722,7 & 12456,5952 & 11706,2 & 750,391 & $95,43 \%$ & 3691,28 \\
9 & 750,391 & 11685,1 & 12426,3826 & 11711,1 & 715,2862 & $95,23 \%$ & 3685,62 \\
10 & 715,2862 & 11734,1 & 12446,462 & 11719,1 & 727,3612 & $94,92 \%$ & 3691,82 \\
\hline
\end{tabular}

1 Inclui os choques de demanda.

O alto estoque inicial da Tabela 3 é compensado por uma redução da área plantada até o ponto em que a disponibilidade alcança patamares normais. No primeiro ano da simulação, a área plantada é baixa. O estoque inicial de 4.000 mil toneladas é reduzido para quase a metade já na primeira safra. Na quarta safra, o valor do estoque já atinge valor próximo ao dos anos subsequentes.

Os Gráficos 6, 7, 8 e 9 mostram a convergência das média de longo prazo para a disponibilidade, consumo, estoque final e preço. Foi considerado como 100\%, para cada parâmetro, 
o primeiro valor encontrado para estoque inicial zero. Percebe-se claramente que os estoques iniciais fora da média são absorvidos de maneira bastante significativa para o quinto ano.

Gráfico 6 - Índice de disponibilidade ao longo de dez anos para estoque inicial zero e 4.000 mil toneladas

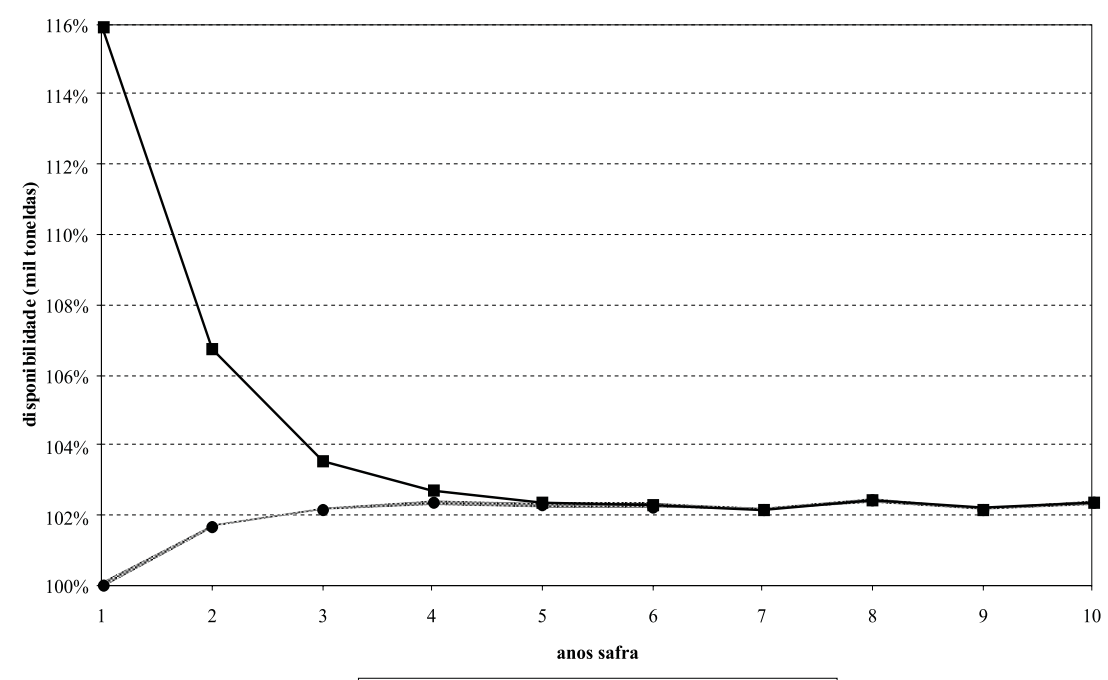

estoque inicial zero - estoque inicial $4.000 \mathrm{mil}$ ton

Gráfico 7 - Índice de consumo ao longo de dez anos para estoque inicial zero e 4.000 mil toneladas

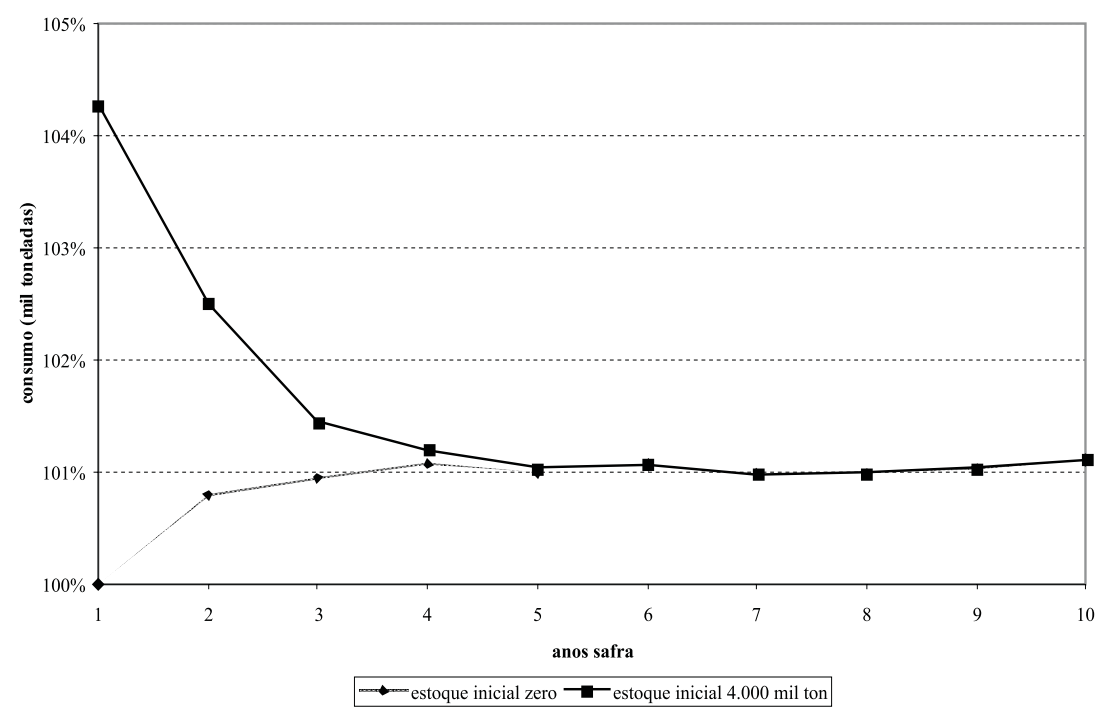


Gráfico 8 - Índice de estoque final ao longo de dez anos para estoque inicial zero e $4.000 \mathrm{mil}$ toneladas

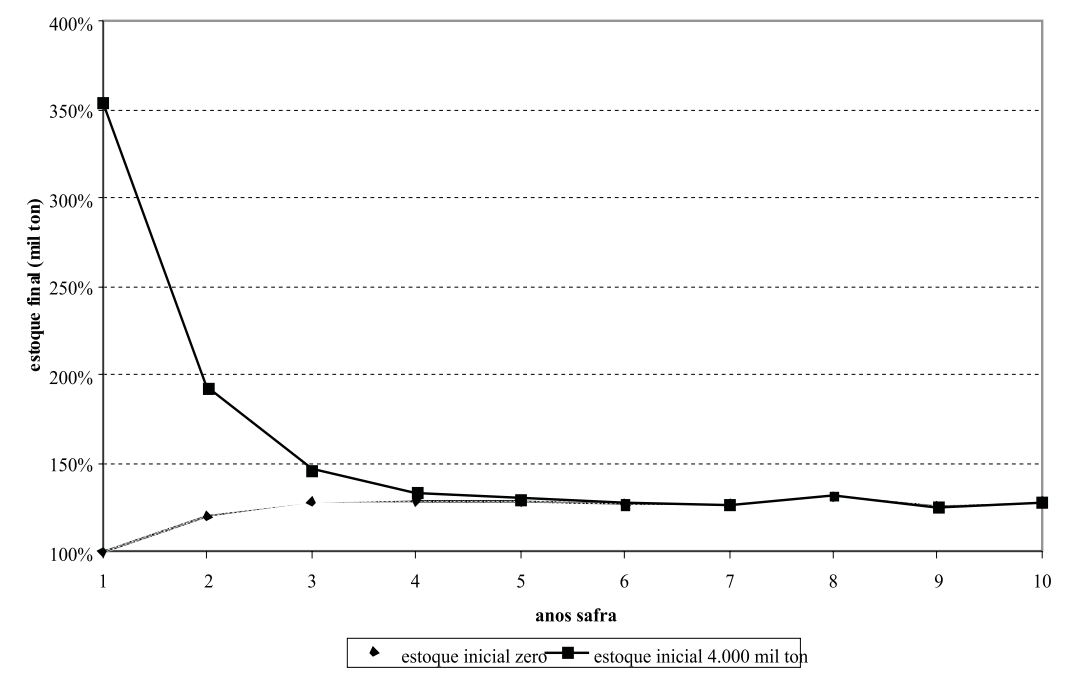

Gráfico 9 - Índice de preços ao longo de dez anos para estoque inicial zero e 4.000 mil toneladas

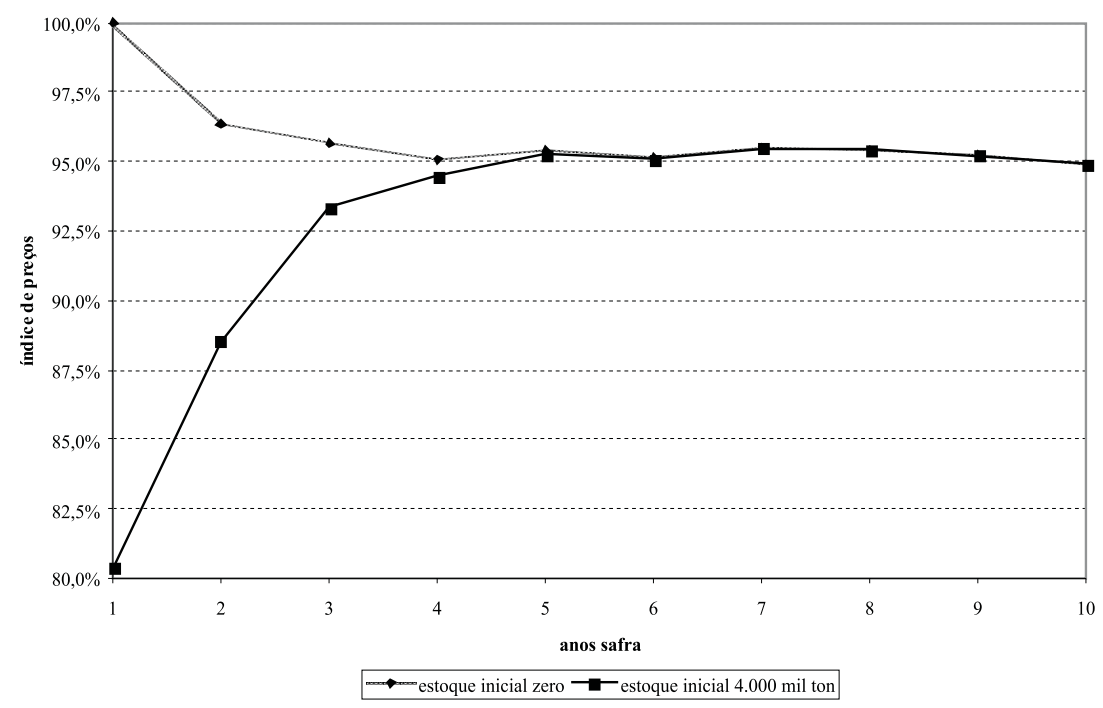

\section{CONCLUSÃO}

Este estudo teve como propósito analisar o armazenamento de arroz no Brasil em condições competitivas, de mercado fechado, sem intervenções do governo e com expectativas racionais.

O caráter dinâmico do modelo do armazenamento é uma característica importante que não tem recebido a devida importância. O problema dinâmico estocástico não possui uma so- 
lução algébrica, o que torna necessária a utilização de métodos numéricos. Como a função do preço esperado não é conhecida, tornou-se necessária a utilização de outros métodos numéricos para tornar possível a solução. Apesar de ter uma formulação aparentemente simples, a resolução do modelo necessita técnicas sofisticadas de cálculo.

Foram necessárias 12 aproximações da função do preço esperado, embora a diferença encontrada entre as aproximações realizadas tenha sido pequena, já a partir da quarta aproximação.

Os resultados demonstram que, na presença da atividade de estocagem, existe uma menor dispersão do consumo ao longo do tempo, o que torna a variação dos preços menores, ou seja, os preços para os anos com baixa produção são menores e os preços para os anos com alta produção são maiores na presença de formação de estoques.

O valor crítico da disponibilidade para que ocorra formação de estoques, encontrado para este modelo, foi de 11.833,47 mil toneladas; para qualquer disponibilidade abaixo deste, não ocorrerá formação de estoques e, para qualquer disponibilidade acima deste valor, haverá formação de estoques.

Safras com baixa ou alta produtividade dão origem a baixos e altos estoques, respectivamente. Nas simulações de longo prazo, pôde-se observar que estes estoques muito fora da média são absorvidos em cerca de três ou quatro períodos.

Os resultados ainda demonstram a consistência do modelo e permitem a visualização de inúmeras aplicações para modelos desta natureza.

\section{REFERÊNCIAS}

AGRIANUAL. O anuário da agricultura brasileira. São Paulo, 2005. 500p.

BARROS, G. S. A. C. Economia da comercialização agrícola. Piracicaba. Disponível em: <http://cepea. esalq.usp.br>. Acesso em: 1 maio 2005.

BRESSLER, R. G.; KING, R. A. Market, prices and interregional trade. New York: John Wiley \& Sons, Inc., 1970.

GUIMARÃES, V. A. Análise de armazenamento de milho no Brasil com um método dinâmico de expectativas racionais. Tese (Doutorado) - Piracicaba, 2001.

GUSTAFSON, R. L. Carryover levels for grains: a method for determining amounts that are optimal under specified conditions. Washington: USDA, 1958 92p. (Technical Bulletin, 1178).

HELMBERGER, P. G.; WEAVER, G. Welfare implications of commodity storage under uncertainty. American Journal of Agricultural Economics, v. 54, n. 4 p. 63-96, 1977.

LOWRY, M.; GLAUBER, J.; MIRANDA, M. J.; HELMBERGER, P. G. Pricing storage of field crops: a quarterly model applied to soybeans. American Journal of Agricultural Economics, v. 69 p. 740-749, 1987. 
MELO-FILHO, G. A.; LEMES, M. M. R. Estimativa do custo de produção de arroz de sequeiro, safra 2000/2001, em Mato Grosso. Embrapa, set. 2000. (Comunicado Técnico, n. 20).

MELO-FILHO, G. A.; RICHETTI, A. Estimativa do custo de produção de arroz de sequeiro, safra 2001/2002, em Mato Grosso. Embrapa, dez. 2001. (Comunicado Técnico, n. 41).

. Estimativa do custo de produção de arroz de sequeiro, safra 2002/2003, em Mato Grosso. Embrapa, out. 2002. (Comunicado Técnico, n. 59).

MIRANDA, M. J.; FACKLER, P. L.Applied computacional economics and finance. Disponível em: < http:// www4.ncsu.edu/ pfackler/compecon/conpecom.pdf>. Acesso em: 12 maio 2001.

WRIGHT, B. D.; WILLIAMS, J. C. The economic role of commodity storage. Economic Journal, v. 92 , p. 596-614, 1982.

. Storage and commodity markets. New York: Cambridge University Press, 1991. 502p. 